\title{
Backward masking in monkeys after foveal prestriate and inferior temporal cortex lesions
}

\author{
D. B. BENDER \\ Division of Neurobiology, Department of Physiology \\ State University of New York at Buffalo, Buffalo, New York 14226 \\ and \\ C. G. GROSS \\ Psychology Department, Princeton University, Princeton, New Jersey 08540
}

\begin{abstract}
In the monkey, foveal prestriate and inferior temporal cortex lesions produce a profound impairment of visual discrimination learning. In this experiment, we examined whether these impairments were associated with a loss of visual sensitivity under conditions of visual masking. Backward masking curves were obtained for two monkeys before and after temporal lobe lesions and for one normal human subject. When tested under the same conditions, human and animal curves were the same. The lesions had no effect on visual masking, although they did impair visual learning.
\end{abstract}

Removal of portions of the inferior temporal cortex of monkeys produces a severe impairment in visual, and only visual, discrimination learning. Although this syndrome has been intensively studied for over two decades, its nature has remained obscure (for reviews, see Dean, 1976; Gross, 1973; Mishkin, 1972). This visual discrimination deficit does not appear to be the result of a "simple sensory loss": inferior temporal lesions that impair visual discrimination learning do not, by contrast, reduce visual acuity or produce detectable scotomata (Cowey \& Weiskrantz, 1967). Because of these results, the visual learning loss has usually been thought to reflect a "higher order" dysfunction. However, it is possible that more subtle sensory or perceptual alterations underlie or at least accompany the visual discrimination loss (Pasik, Pasik, Battersby, \& Bender, 1958). As a test of this possibility, backward masking functions were obtained for monkeys with temporal lesions.

"Backward masking" refers to the decrease in detectability of a brief target stimulus when followed by a spatially overlapping and usually brighter masking stimulus. The degree of interference or masking decreases as the interstimulus interval increases, and the shape of this function is dependent on several parameters, such as relative stimulus luminance, amount of contour, and monoptic or dichoptic viewing (for reviews, see Breitmeyer \& Ganz, 1976; Kahneman, 1968). In the present experiment, the tar-

This research was supported in part by NIH Grants EY02254 and MH-19420 and NSF Grant BNS-7905589. We thank Susan Wolf for secretarial assistance. get stimulus was a letter and the masking stimulus a checkerboard pattern.

In human patients, backward masking curves have been useful in detecting subtle changes in the visual fields following visual system damage: backward masking curves are depressed in portions of the hemifield that appear normal in standard perimetric testing (Battersby, Wagman, Karp, \& Bender, 1960). Thus, masking curves are appropriate candidates for detecting changes in visual processing that might follow inferior temporal lesions in monkeys.

A second purpose of this study was to compare the effects on a psychophysical task of classical inferior temporal lesions (i.e., restricted to cytoarchitectonic area TE) with the effects of foveal prestriate lesions. Foveal prestriate lesions include both the inferior temporal cortex posterior to area TE and the ventrolateral prestriate cortex that receives a projection from the foveal representation in striate cortex. Both inferior temporal and foveal prestriate lesions impair visual discrimination, but the two impairments differ in several ways (Gross, 1973). However, there are no data on possible visual sensory deficits after foveal prestriate lesions, except for the recent demonstrations that they have little effect on angular discrimination thresholds (Blake, Jarvis, \& Mishkin, 1977; Dean, 1978).

A third purpose of this experiment was to compare backward masking by pattern in man and monkey.

\section{METHODS}

\section{Subjects}

Two adolescent Macaca mulatta (Paul and Richard) and one experienced college student (D.J.) served as subjects. The morikeys were water deprived during testing and were reinforced by $.25 \mathrm{cc}$ 
of orange juice for each correct response. The human was paid 1 cent for each correct response. Prior to surgery, both monkeys had their absolute thresholds for the detection of a brief light flash determined, learned a simultaneous pattern discrimination, and then were tested on the masking task. Following surgery, they were tested for retention of the pattern discrimination, learned a new pattern discrimination, had their thresholds remeasured, and then were retested on the masking task. As reported elsewhere (Bender, 1973), both animals showed a pattern discrimination learning deficit, but no increase in absolute visual thresholds.

\section{Apparatus}

The test chamber has been described in detail previously (Bender, 1973). The stimuli were presented on two translucent response keys whose diameters were $2.8 \mathrm{~cm}$ and which were mounted $5 \mathrm{~cm}$ apart and $9 \mathrm{~cm}$ above a third key, response to which started a trial. The target stimulus (TS) was a luminous letter $O\left(1.3 \mathrm{~cm}\right.$ diameter, approximately $7^{\circ}$ visual angle) presented on a black background on the left key for $14.9 \mathrm{msec}$. The masking stimulus (MS) was a checkerboard pattern made up of $.5 \times .5 \mathrm{~cm}$ (approximately $3^{\circ}$ visual angle) black and white squares which completely filled the response key. Its average luminance was $1.2 \mathrm{fL}$, and its duration was $45 \mathrm{msec}$. Four interstimulus intervals (ISI) were used: 10, 20, 35, and $60 \mathrm{msec}$.

\section{Behavioral Procedures}

The subjects were dark adapted and then run in the darkened test chamber for 400 trials per day. The first 25 trials of each session were "warm-up" trials and were not used in the data analysis.

The start key was illuminated with a dim red light. Response to this key turned off the red light and initiated the stimulus sequence $400 \mathrm{msec}$ later. On $55 \%$ of the trials (stimulus trials), the TS was presented on the left key and was followed at one of the four ISIs by the MS on both keys. On $45 \%$ of the trials (no-stimulus trials), the TS was not presented, but after one of the four ISIs, the MS was presented on both keys. The order of the stimulus and no-stimulus trials and of the ISIs was determined from a random-number table. The subjects were reinforced for responding to the left key on stimulus trials and to the right key on no-stimulus trials. Following either response, a 5-sec intertrial interval was initiated, which was reset by a response to any key and which was terminated by illumination of the start key, providing the subject with the opportunity to initiate a new trial.

First, the subjects were trained with the TS easily visible and the MS barely visible until performance was $90 \%$ correct at all ISIs. During the next few sessions, the MS luminance was gradually increased to its final value of $1.2 \mathrm{fL}$. Then the TS luminance was decreased in 1-dB steps every one or two sessions until performance at the shortest ISI was less than $15 \%$ correct or until performance at the $35-\mathrm{msec}$ ISI was below $80 \%$ correct. Testing continued at this final TS luminance until a subject's data showed no significant trend for 5 (D.J.) or 10 (Paul and Richard) successive sessions. The final TS luminance before operation was $.015 \mathrm{fL}$ for Richard and D.J. and $.03 \mathrm{fL}$ for Paul. This training procedure was followed in obtaining masking curves both before and after the lesions.

The detection rate at each ISI was corrected for chance by the formula: $\%$ correct $=(\mathrm{Pcd}-\mathrm{Pfa}) /(1-\mathrm{Pfa})$, where $\mathrm{Pcd}$ is the proportion of correct detections and $\mathrm{Pfa}$ the proportion of false alarms (Green \& Swets, 1966). False-alarm rates varied from session to session and among subjects, but typically were between $10 \%$ and $40 \%$.

\section{Surgery and Histology}

Richard received a bilateral inferior temporal cortex lesion, and Paul received a bilateral foveal prestriate lesion. Details of the surgery and histology have been published (Bender, 1973). Briefly, Richard's lesion was confined to area TE and did not encroach upon either the temporal pole or foveal prestriate cortex. Thalamic retrograde degeneration was confined to the caudoventral part of the pulvinar. Paul's lesion included all lateral prestriate cortex between the lunate and superior temporal sulci and encroached very slightly on area TE and, in the right hemisphere, on striate cortex. There was slight retrograde degeneration in both the inferior division of the pulvinar and in the right lateral geniculate body.

\section{RESULTS AND DISCUSSION}

Detectability of the target stimulus as a function of the interstimulus interval for all subjects is shown in Figure 1. The backward masking curves were similar for the human and monkey subject tested with the same target luminance. Adkins, Fehmi, and Lindsley (1969) used a diffuse light or "blanking" stimulus as the masking stimulus and obtained results similar to those of the present study, which used a pattern as the masking stimulus.

The detectability of the target recovered almost twice as fast when the target luminance was doubled. That is, the slope of the masking curve was $.41 \% / \mathrm{msec}$ with the .03-fL target luminance (Paul) and $.18 \% / \mathrm{msec}$ with a .15-fL target luminance (Richard). Similar results have been found in man (e.g., Schiller, 1966).

There were no effects of either the inferior temporal lesion or the foveal prestriate lesion on the backward masking curves, although both animals did show impaired visual discrimination learning. This result lends further support to the suggestion that the visual learning deficit that follows temporal lobe lesions is not the result of even a relatively subtle sensory deficit. Absolute thresholds, critical flicker frequency, and backward masking functions all appear normal in the inferotemporal monkey (Bender, 1973; Symmes, 1965). Yet these are the very measures most sensitive in demonstrating an amblyopia in the clinic.

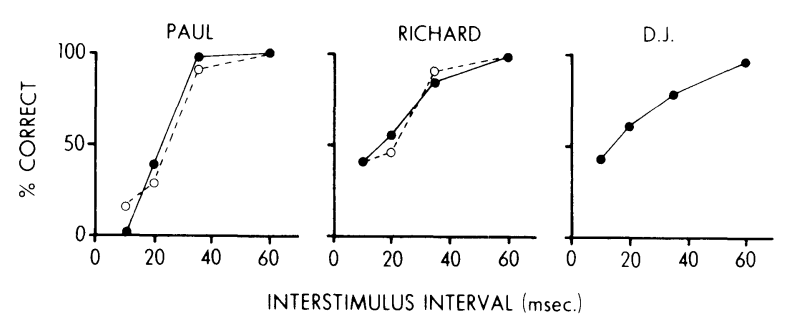

Figure 1. Backward masking curves for all subjects. Each point is the target stimulus detection rate, corrected for chance, averaged over 10 asymptotic sessions. Solid lines and closed circles: preoperative data. Dotted lines and open circles: postoperative data. Target luminance for Paul is $.03 \mathrm{fL}$, for Richard and D.J., .015 fL. Average mask luminance was $1.2 \mathrm{fL}$ for all subjects. 


\section{REFERENCES}

Adkins, J. W., Fehmi, L. G., \& Lindsley, D. B. Perceptual discrimination in monkeys: Retroactive visual masking. Physiology \& Behavior, 1969, 4, 255-259.

Battersby, W. S., Wagman, I. H., Karp, E., \& Bender, M. B. Neural limitations of visual excitability: Alterations produced by cerebral lesions. Archives of Neurology, 1960, 3, 24-42.

BENDER, D. B. Visual sensitivity following inferotemporal and foveal prestriate lesions in the Rhesus monkey. Journal of Comparative and Physiological Psychology, 1973, 84, 613-621.

Blake, L., Jarvis, C. D., \& Mishkin, M. Pattern discrimination thresholds after partial inferior temporal or lateral striate lesions in monkeys. Brain Research, 1977, 120, 209-220.

Breitmeyer, B. G., \& GANZ, L. Implications of sustained and transient channels for theories of visual pattern masking, saccadic suppression, and information processing. Psychological Review, 1976, 83, 1-36.

Cowey, A., \& Weiskrantz, L. A comparison of the effects of inferotemporal and striate cortex lesions on the visual behavior of rhesus monkeys. Quarterly Journal of Experimental Psychology, 1967, 19, 246-253.

DEAN, P. Effects of inferotemporal lesions on the behavior of monkeys. Psychological Bulletin, 1976, 83, 41-71.
DEAN, P. Visual cortex ablation and thresholds for successively presented stimuli in rhesus monkeys. Experimental Brain $R e$ search, 1978, 32, 445-458.

Green, D. M., \& Swets, J. A. Signal detection theory and psychophysics. New York: Wiley, 1966.

Gross, C. G. Inferotemporal cortex and vision. In E. Stellar \& J. M. Sprague (Eds.), Progress in physiological psychology (Vol. 5). New York: Academic Press, 1973.

Kahneman, D. Method, findings and theory in studies of visual masking. Psychological Bulletin, 1968, 70, 404-425.

Mishin, M. Cortical visual areas and their interactions. In A. G. Karczmar \& J. C. Eccles (Eds.), The brain and human behavior. Berlin: Springer, 1972.

Pasik, T., Pasik, P., Battersby, W. S., \& Bender, M. B. Target size and visual form discrimination in monkeys with bitemporal lesions. Federation Proceedings, 1958, 17, 481.

Schille R, P. H. Forward and backward masking as a function of relative overlap and intensity of test and masking stimuli. Perception \& Psychophysics, 1966, 1, 161-164.

Symmes, D. Flicker discrimination by brain-damaged monkeys. Journal of Comparative and Physiological Psychology, 1965, 60, 470-473.

Manuscript received February 10, 1981; revision accepted for publication July 31,1981 .) 